\title{
A AUTOCOMPOSIÇÃO COMO POLÍTICA PÚBLICA DE INCENTIVO AO DIREITO FUNDAMENTAL DE ACESSO À JUSTIÇA ${ }^{1}$
}

Fabiana Marion Spengler ${ }^{2}$

\section{Resumo}

O presente artigo trata sobre a autocomposição como política pública de incentivo ao direito fundamental de acesso à justiça. O objetivo da pesquisa é discutir o incentivo à autocomposição enquanto política pública de fomento ao direito fundamental de acesso à justiça. O texto aborda o conceito de acesso à justiça e os esforços feitos para concretizá-lo após a CF/88 e EC 45. Pretendeu-se debater o conceito e a classificação das políticas públicas. Em vista de tal contexto, discorreu-se sobre a autocomposição no CPC. O método de abordagem utilizado foi o dedutivo. Já o método de procedimento utilizado foi o monográfico.

Palavras-chave: Acesso à justiça. Autocomposição. Código de Processo Civil. Política Pública. Direito Fundamental.

\section{SELF-COMPOSITION AS A PUBLIC POLICY TO ENCOURAGE THE FUNDAMENTAL RIGHT OF ACCESS TO JUSTICE}

\begin{abstract}
This article deals with "Self-composition as a public policy that encourages the fundamental right of access to justice". The objective of the research is to discuss the incentive to selfcomposition as a public policy to promote the fundamental right of access to justice. In addition, addressing the concept of access to justice and the efforts made after CF 88 and EC 45. It was intended to discuss the concept and classification of public policies. And, in view of such context, discuss the self-composition in the CPC. The approach method used was the deductive. The procedure method used was the monographic.
\end{abstract}

\footnotetext{
${ }^{1} \mathrm{O}$ presente texto foi produzido a partir da pesquisa desenvolvida no projeto: “ $\mathrm{O}$ presente texto foi produzido no âmbito do projeto: "O terceiro e o conflito: o mediador, o conciliador, o juiz, o árbitro e seus papeis políticos e sociais", financiado pela Fundação de Amparo a Pesquisa do Estado do Rio Grande do Sul, no Edital 02/2017, PqG FAPERGS, Pesquisador Gaúcho, processo nº17/2551-0001169-4

2 Bolsista de Produtividade em Pesquisa do CNPq (Pq2). Pós-doutora em Direito pela Università degli Studi di Roma Tre, em Roma, na Itália, com bolsa CNPq (PDE). Doutora em Direito pelo programa de Pós-Graduação stricto sensu da Universidade do Vale do Rio dos Sinos - UNISINOS - RS, com bolsa Capes, mestre em Desenvolvimento Regional, com concentração na área Político Institucional da Universidade de Santa Cruz do Sul - UNISC - RS, docente dos cursos de Graduação e Pós Graduação lato e stricto sensu da UNISC, Coordenadora do Grupo de Pesquisa "Políticas Públicas no Tratamento dos Conflitos" vinculado ao CNPq; coordenadora do projeto de pesquisa "O terceiro e o conflito: o mediador, o conciliador, o juiz, o árbitro e seus papeis políticos e sociais" financiado pela Fundação de Amparo à Pesquisa do Estado do Rio Grande do Sul Fapergs, Edital 02/2017 - PqG - Pesquisador Gaúcho, coordenadora e mediadora do projeto de extensão: "A crise da jurisdição e a cultura da paz: a mediação como meio democrático, autônomo e consensuado de tratar conflitos" financiado pela Universidade de Santa Cruz do Sul - UNISC; autora de diversos livros e artigos científicos, e-mail: fabiana@unisc.br, link currículo Lattes: http://lattes.cnpq.br/8254613355102364. Endereço para correspondência: Rua Dona Flora, 958, Bairro Universitário, Santa Cruz do Sul - RS, CEP 96815 640, telefone: (51) 999330194.
} 
Keywords: Access to justice. Self composition. Code of Civil Procedure. Public policy. Fundamental right.

\section{Notas Introdutórias}

A Constituição Federal de 1988 garantiu o acesso à justiça ${ }^{3}$ aos hiposuficientes no texto do art. $5^{\circ}$, inciso LXXIV e do art. 134. Décadas se passaram e o Judiciário brasileiro encontra-se em dificuldades para responder a todas as demandas a ele direcionadas.

Essa dificuldade pode ser vislumbrada junto ao Relatório Justiça em Números (CNJ, 2018, <http://www.cnj.jus.br>) de 2018, referente ao ano base de 2017. Neste relatório observa-se, dentre outras coisas, que a taxa de congestionamento ${ }^{4}$ do Judiciário gira em torno de $70 \%$, ou seja, esse é o percentual médio de processos que passam de um ano para outro sem julgamento. A taxa de congestionamento tem se mantido estável nos últimos anos, não obstante a existência de várias iniciativas ${ }^{5}$ no sentido de melhorar o acesso à justiça e a resposta jurisdicional, especialmente tornando mais célere o processo.

Diante da insuficiente resposta as iniciativas até então propostas, para melhorar o acesso à justiça e efetuar uma prestação jurisdicional adequada, em 2015 entrou em vigor o Código de Processo Civil atual que trouxe, em seu texto, a autocomposição ${ }^{6}$ como meio consensuado e mais célere de lidar com os conflitos, além de caminho para o descongestionamento judicial.

Partindo dessa realidade o presente texto tem como tema debater o acesso à justiça como direito fundamental e as políticas públicas, aqui mais especificamente a autocomposição, como meio de garanti-lo. O problema de pesquisa que norteou a investigação questiona se a autocomposição prevista no atual CPC é uma política pública de incetivo ao direito fundamental de acesso à justiça no Brasil no pós Constituição de 1988. A hipótese responde de modo afirmativo ao problema de pesquisa.

\footnotetext{
${ }^{3}$ Importante referir que o presente texto analisará o acesso à justiça em seu sentido amplo, no qual encontra-se contido o acesso à jurisdição. Sobre esse assunto discorre o primeiro item do texto.

${ }^{4}$ Taxa de Congestionamento: indicador que mede o percentual de casos que permaneceram pendentes de solução ao final do ano-base, em relação ao que tramitou (soma dos pendentes e dos baixados). Cumpre informar que, de todo o acervo, nem todos os processos podem ser baixados no mesmo ano, devido a existência de prazos legais a serem cumpridos, especialmente nos casos em que o processo ingressou no final do ano-base (CNJ, 2018, p. 72). ${ }^{5}$ É possível exemplificar apontando a Emenda Constitucional 45 de 2004, a criação das Metas pelo Conselho Nacional de Justiça - CNJ, a Resolução 125/2010 do CNJ e a Resolução 174 do Conselho Superior da Justiça do Trabalho - CSJT, dentre outras.

${ }^{6}$ Art. 139, inciso V, art. 165, 166, art. 190, art. 334, art. 515, dentre outros.
} 
Do problema de pesquisa nasceu o objetivo: discutir o incentivo à autocomposição enquanto política pública de fomento ao direito fundamental de acesso à justiça e o modo como esse acesso vem se concretizando no Brasil atualmente.

Para cumprir com o objetivo proposto o método de abordagem utilizado foi o dedutivo. Como método de procedimento foi utilizado o método monográfico e como técnica de pesquisa aplicou-se a bibliográfica.

Primeiramente o texto abordou o conceito de acesso à justiça e os esforços feitos, especialmente depois da Constituição de 1988 e da Emenda Constitucional 45 (EC 45/2004), para viabilizar esse direito de modo quantitativo, e, principalmente, qualitativamente mais adequado.

Posteriormente, foram debatidos o conceito e a classificação das políticas públicas para no item final analisar a autocomposição como uma delas que tem por meta fomentar o acesso à justiça no período posterior a Constituição de 1988. Nesse item o texto discorre sobre a autocomposição contida no atual CPC brasileiro.

Este é, pois, o texto que agora se apresenta.

\section{O direito humano fundamental de acessar à justiça}

Para fins de discutir o acesso à justiça como um direito humano fundamental é importante antes definir tal expressão. Para compor a definição de acesso à Justiça, Mauro Cappelletti e Bryant Garth (2002) delineiam duas hipóteses: a) o método por intermédio do qual as pessoas obtêm resultados individuais e socialmente justos; b) o método pelo qual as pessoas podem reivindicar seus direitos ou tratar seus conflitos no esteio estatal. Conforme os autores, este tema está amplamente ligado ao binômio possibilidade-viabilidade de acessar o Sistema Jurídico em igualdade de condições. Tal prerrogativa foi democraticamente conquistada pelos cidadãos, sob a forma de Direito Humano básico.

Assim, parafraseando Mauro Cappelletti e Bryant Garth (1988), pode-se dizer, com simplicidade, que este tema está amplamente ligado ao binômio possibilidade-viabilidade de acessar o sistema jurídico em igualdade de condições. Esta prerrogativa foi democraticamente conquistada pelos cidadãos, sob a forma de “o mais básico dos Direitos Humanos”. Liga-se, também, à busca de tutela específica para o direito e/ou interesse ameaçado e, por óbvio, com a produção de resultados justos e efetivos. 
Esta preocupação evidencia a permanente procura pela efetividade do direito e da justiça no caso concreto. Nasce desvinculada de seu germe quando da dedução em juízo, ou melhor, no processo, procura-se apenas a obtenção de sua conclusão formal, pois o resultado final almejado em qualquer querela deve ser, na sua essência, pacificador do conflito. É só assim que se estará efetivando ${ }^{7}$ a chamada Justiça Social, expressão da tentativa de adicionar ao Estado de Direito uma dimensão social (BOLZAN DE MORAIS; SPENGLER, 2019).

Persistir em analisar o processo sob a dimensão da efetividade notoriamente restrita seria atender apenas ao seu escopo jurídico e, hoje, essa noção deve englobar a eliminação de insatisfações, o cumprimento do direito com justiça, a participação ativa dos indivíduos, além de constituir inspiração para o exercício e respeito dos direitos e da própria cidadania. Mas, para tal, há a necessidade de adequação do processo, pois o que se tem assistido é o somatório de insatisfações e decepções experimentado pelos indivíduos, o que acaba por abalar e desgastar a credibilidade que o sistema ainda dispõe. Este paulatino descrédito vem firmando raízes a partir e conforme se evidenciam as debilidades e impossibilidades de o mesmo atender a tão complexa tarefa.

Essa adequação será alcançada com uma "mudança de paradigma”, que só será obtida a partir da formação de uma consciência que rompa posturas anteriores marcadas pela introspecção e que passe a considerar o mundo político e social (a realidade da vida) que rodeia o processo.

Esses pontos vitais referem-se aos diversos escopos da jurisdição e englobam os problemas essenciais da efetividade do processo (BOLZAN DE MORAIS; SPENGLER, 2019). Assim:

As tradicionais limitações ao ingresso na justiça, jurídicas ou de fato (econômicas, sociais), refletem em decepções ${ }^{8}$ para a potencial clientela do Poder Judiciário.

Essas limitações fáticas se referem ao custo do processo e à miserabilidade das pessoas, o que assola a universalidade ${ }^{9}$ da tutela jurisdicional, expressa de forma solene pela Constituição, no seu artigo $5^{\circ}$, LXXIV.

\footnotetext{
${ }^{7}$ A concepção de efetividade que se pretende trabalhar aqui assume um caráter mais amplo do que aquela desenvolvida por Chiovenda cuja visão, de cunho essencialmente individualista, está ultrapassada, pois [...] na medida do que for praticamente possível o processo deve proporcionar a quem tem um direito tudo aquilo e precisamente aquilo que ele tem o direito de obter (CHIOVENDA, 1930, p. 110).

${ }^{8}$ É interessante reforçar que o distanciamento e a descrença do cidadão comum pela jurisdição se dão não só quanto aos seus aspectos quantitativos (velocidade da prestação jurisdicional), mas também nos seus aspectos qualitativos (por exemplo, o problema da discricionariedade judicial). O problema reside, também, na forma como o juiz decide e não só na celeridade de sua decisão.
} 
As limitações jurídicas também configuram estreitamentos das vias de acesso à Justiça. Refere-se aqui, à legitimatio ad causam ativa que, essencialmente individualista, restringe-se a dar a cada um o que é seu, sem manter uma visão solidarista, supraindividual, que se caracteriza por tratar o indivíduo como membro integrante de um grupo social e procurar tecer soluções condizentes com os interesses envolvidos (BOLZAN DE MORAIS; SPENGLER, 2019).

Tais limitações, como se pode observar, privam inúmeras pessoas da tutela jurisdicional, o que lhes causa dano substancial, pois quem não vem a juízo ou não pode fazêlo, renuncia àquilo que aspira ou busca satisfazer suas pretensões por outros meios.

Vencidas as limitações tradicionais e desobstruídas as vias de acesso ao processo, deve-se viabilizar o acesso à ordem jurídica justa, que só se concretizará pela observância das garantias constitucionais do due process of law e da inafastabilidade do controle jurisdicional.

Por outro lado, a eliminação dos litígios deve atender ao critério de Justiça, que figura como objetivo-síntese da jurisdição no plano social ou, do contrário, se teria mera sucessão de arbitrariedades.

Inobstante percorridos os problemas anteriores, o sistema, através de seus operadores, deve estar preparado para produzir decisões que sejam capazes de propiciar a tutela mais ampla possível aos direitos reconhecidos. Refere-se aqui, a utilidade das decisões (BOLZAN DE MORAIS; SPENGLER, 2019).

Perquirindo sobre as garantias constitucionais do processo, conclui-se que o processo é um fenômeno que atinge alguns dos mais fundamentais "Direitos Humanos" (CAPPELLETI, 1994, p. 13). O direito a um juiz imparcial corresponde à garantia da independência da magistratura diante do poder político, e essa imparcialidade é quanto ao conteúdo da controvérsia, e não quanto ao andamento da relação processual, posto que o juiz deve assegurar o desenvolvimento do processo de maneira regular, rápida e leal, dentro de suas possibilidades.

$\mathrm{O}$ due process of law ou o devido processo legal e o contraditório processual implicam, obviamente, o direito de ambas as partes serem ouvidas. Aqui, Cappelletti (1994) aproveita para remeter este princípio ao estudo que se está introduzindo, referindo-se ao

\footnotetext{
${ }^{9}$ O princípio da universalidade, aqui falado, fica prejudicado pelo fato de os hipossuficientes, sem condições financeiras para suportar os gastos de um litígio em juízo, ficarem impedidos de levar ao Judiciário suas lides. Também, refere-se à apreensão sentida por todos, em face do investimento que são obrigados a fazer para litigar, sem a certeza dos resultados, o que configura, em relação ao primeiro, um mal a ser eliminado de semelhante dificuldade.
} 
acesso à Justiça, como espelho da cultura de uma época, pois como diz, “[...] Que princípio é este, se há casos, em que, por razões econômicas, culturais e sociais, a parte não se encontra em condições de se fazer ouvir’? (BOLZAN DE MORAIS; SPENGLER, 2019, p. 34) Por outro lado também é necessário questionar: que jurisdição é essa que, quando ouve responde tardiamente a tal ponto de sua resposta/decisão chegar "a destempo" e já não responder de maneira adequada ao conflito social?

Mas, como se sabe, o acesso à justiça não se esgota no acesso ao Judiciário, traduzindo-se no direito de acesso a uma justiça organizada de forma adequada, cujos instrumentos processuais sejam aptos a realizar, efetivamente, os direitos assegurados ao cidadão $^{10}$. É por isso que não basta apenas "garantir o acesso aos tribunais, mas principalmente possibilitar aos cidadãos a defesa de direitos e interesses legalmente protegidos através de um acto de jurisdictio (CANOTILHO, 2000, p. 243)”.

Consequentemente, essas novas garantias constitucionais vêm para integrar o sentido includente que deve ser conferido às normas constitucionais de um País que pretende reduzir desigualdades, erradicar a pobreza, fundar uma sociedade justa e solidária, etc, como forma de integrar a nação em um projeto de sociedade comprometida com a dignidade humana que, como escopo do "constitucionalismo social e democrático de direito", repercute em todos os âmbitos da prestação estatal, seja administrativa ou jurisdicional (BOLZAN DE MORAIS, 2005, p. 18).

Observa-se então que o acesso à Justiça brasileiro se transformou ao longo do tempo e foi atingido pelas modificações sofridas pela Constituição e pelo Processo Civil brasileiros. Quando o direito de acesso à Justiça passou a fazer parte da última Constituição (art. $5^{\circ}$, $\mathrm{XXXV),} \mathrm{criaram-se} \mathrm{caminhos} \mathrm{para} \mathrm{torná-lo} \mathrm{viável} \mathrm{a} \mathrm{todos,} \mathrm{assegurando} \mathrm{o} \mathrm{direito} \mathrm{à} \mathrm{gratuidade}$ para o hipossuficiente.

Porém, não obstante os dispositivos constitucionais e as leis esparsas, tornou-se comum confundir acesso à Justiça com acesso ao Judiciário. Encontram-se, com certa frequência, estudos que se referem a ambos como sinônimos, ignorando que o acesso ao

\footnotetext{
10 "Uma tarefa básica dos processualistas modernos é expor o impacto substantivo dos vários mecanismos de processamento de litígios. Eles precisam, consequentemente, ampliar sua pesquisa para além dos tribunais e utilizar métodos de análise da sociologia, da política, da psicologia e da economia, e ademais, aprender através de outras culturas. O "acesso" não é apenas um direito social fundamental, crescentemente reconhecido; ele é, também, necessariamente, o ponto central da moderna processualística. Seu estudo pressupõe um alargamento e aprofundamento dos objetivos e métodos da moderna ciência jurídica" (CAPPELLETTI, 1988, p. 13).
} 
Judiciário está contido no acesso à Justiça, que é mais amplo e assegura maior hipótese de tutela aos direitos do cidadão.

A concepção que equipara o acesso à Justiça com o "acesso aos tribunais" faz parte de "um conceito estrito". Por outro lado, considera-se um conceito mais amplo aquele que "trata do acesso à justiça como o acesso aos meios de desenvolvimento social, político e econômico de um Estado, ou seja, uma justiça social, distributiva" (MADERS, 2013, p. 56). Esse "conceito estrito" de acesso à Justiça está intimamente ligado aos diversos escopos da jurisdição e engloba os problemas essenciais da efetividade do processo. Assim, as tradicionais limitações ao ingresso na Justiça, jurídicas ou de fato (econômicas, sociais), refletem em decepções para a potencial clientela do Poder Judiciário.

\section{Aspectos teóricos da autocomposição enquanto política pública}

Mais que um meio de acesso à justiça, fortalecedor da participação social do cidadão, a autocomposição é política pública que vêm ganhando destaque e fomento do Ministério da Justiça, da Secretaria de Reforma do Judiciário, do CNJ e do legislador brasileiro, uma vez que resta comprovada empiricamente sua eficiência no tratamento de conflitos.

Porém, para classificar e discorrer a respeito da autocomposição enquanto política pública, é importante salientar que a expressão "política pública" ${ }^{11}$ é definida como um programa ou quadro de ação governamental, porque consiste num conjunto de medidas articuladas (coordenadas), cujo escopo é dar impulso, isto é, movimentar a máquina do governo, no sentido de realizar algum objetivo de ordem pública ou, na ótica dos juristas, concretizar um direito (BUCCI, 2006, p. 14).

Uma definição "funcional” de política pública é: “a policy-making trata fundamentalmente de atores cercados de restrições que tentam compatibilizar objetivos políticos (policy goals) com meios políticos (policy means), num processo que pode ser

\footnotetext{
${ }^{11}$ No entanto, é interessante diferenciar as expressões "política" de "política pública" uma vez que a primeira significa a "ordenação institucional, segundo recursos de autoridade, dos interesses sociais em disputa, independentemente das fórmulas de competição particulares adotadas em quaisquer que sejam os fundamentos materiais e ideais dos interesses concretos envolvidos". Já por política pública se entende as "traduções técnicoracionais de soluções específicas do referido jogo de interesses da política" (REIS, 1989, p. 113 - 114). Ainda na busca de diferenciações entre as expressões "política" e "política pública", avista-se a necessidade de analisar a polissemia de tais termos. Começando por "política" é possível se valer da língua inglesa para demonstrar a dita polissemia. Essa língua traz expressões diferentes para designar os sentidos que as línguas latinas reúnem sob o termo política. Designando a esfera política em contraposição a uma esfera da sociedade civil, usa-se polity, enquanto politics designa a atividade política e policies a ação pública (MULLER; SUREL, 1998, p. 13).
} 
caracterizado como "resolução aplicada de problemas". Os autores vão além, definindo que identificar os problemas e aplicar (por mais imperfeitas que sejam) as soluções encontradas, envolvem a articulação de objetivos políticos por meio de deliberações e discursos, além do uso de instrumentos políticos (policy tools) numa tentativa de atingir esses objetivos (HOWLETT; RAMESH; PERL, 2013, p. 5-6).

Para fins de estudar política pública como um processo aplicado a resolução de determinado problema, existem três pontos centrais que podem ser assim resumidos: "a) o agente primário da policy-making pública é um agente do governo; b) a policy-making envolve uma decisão fundamental por parte dos governos de fazer ou não alguma coisa a respeito de um problema e esta decisão é tomada pelos políticos eleitos e outros funcionários oficiais. " Assim, ela é uma escolha feita no sentido de empreender um determinado curso em ação; “c) a política pública é uma determinação consciente de um governo" (HOWLETT; RAMESH; PERL, 2013, p. 6-7).

É possível afirmar (MASSA-ARZABE, 2006, p. 60) que "a utilização da expressão política pública serve não só para designar a política do Estado, mas a política do público, de todos"12. A autora refere que "trata-se da política voltada a fazer avançar os objetivos coletivos de aprimoramento da comunidade e da coesão - ou da interdependência - social".

Em apertada síntese que envolve as afirmações dos autores antes referidos, João Pedro Schmidt (2018, p. 127) propõe-se a seguinte definição para política pública: “é um conjunto de decisões e ações adotadas por órgãos públicos e organizações da sociedade, intencionalmente coerentes entre si, que, sob coordenação estatal, destinam-se a enfrentar um problema político".

De fato, toda política pública é uma forma de intervenção nas relações sociais, objetivando enfrentar um problema político, estando sempre condicionada pelos interesses e expectativas dos integrantes de tais relações. Por conseguinte, "ela pode ser definida como a busca explícita e racional de um objetivo, graças à alocação adequada de meios que, mediante uma utilização razoável, devem produzir consequências positivas" (GRAU, 2000, p. 26).

No caso da autocomposição como política pública, observa-se seu papel no cumprimento de um objetivo que é, dentre outras coisas, proporcionar um acesso à justiça

\footnotetext{
${ }^{12}$ Nesse sentido que existem elementos que são comuns nas definições de política pública tais como: a) a política pública é feita em nome do público; b) é geralmente feita ou iniciada pelo governo; c) é interpretada e implementada por atores públicos e privados; d) é o que o governo pretende fazer; e) é o que o governo escolhe não fazer (DIAS; MATOS, 2012, p. 13 e seguintes).
} 
adequado e eficiente no tratamento dos conflitos sociais. Necessita para ser implementadas da alocação de meios (recursos humanos, treinamento adequado e estrutura) por parte da administração pública. Nesse sentido, a autocomposição pode ser apontada como uma política pública, uma vez que se trata de um “conjunto de programas de ação governamental estáveis no tempo, racionalmente moldadas, implantadas e avaliadas, dirigidas à realização de direitos e de objetivos social e juridicamente relevantes". Tais conjuntos de programas governamentais são identificados com a "distribuição e redistribuição de bens e posições que concretizem oportunidades para cada pessoa viver com dignidade e exercer seus direitos" de modo a assegurar-lhe recursos e condições para a ação, assim como a liberdade de escolha para fazerem uso desses recursos (MASSA-ARZABE, 2006, p. 63).

Além disso, a autocomposição é uma política pública classificada como política de estado uma vez que expressa "opções amplamente respaldadas pelas forças políticas e sociais, têm previsão legal e contam com mecanismos e regulamentações para a sua implementação" As políticas de estado "atravessam" governos de diferentes concepções ideológicas justamente por estarem entranhadas no aparato estatal e terem ampla legitimação. Caracterizar uma política como sendo "de estado" não é conferir um "qualificativo de excelência éticopolítica e sim reconhecer que ela reúne condições para se prolongar no tempo. Assim, ao contrário das políticas de governo que "tendem a ser provisórias" as "políticas de estado, duradouras" (SCHMIDT, 2018, p. 127) ${ }^{13}$.

Para fins de atingir seus objetivos, as políticas públicas são formuladas mediante um processo que engloba todo o procedimento de discussão, aprovação e implementação das mesmas.

Especialmente nos sistemas democráticos, esses processos desenvolvem-se num cenário político no qual atuam diversos e distintos "atores políticos" (ou "jogadores", especificamente referindo-se a teoria dos jogos). ${ }^{14}$ Entre os jogadores que participam desse “jogo" encontram-se atores estatais oficiais e políticos profissionais (presidentes, líderes de partidos, legisladores, juízes, governadores, burocratas), assim como grupos privados,

\footnotetext{
${ }^{13}$ Conforme pode-se verificar no texto citado esse autor utiliza as expressões "política" e "política pública" no mesmo contexto e como sinônimos.

${ }^{14}$ A teoria dos jogos consiste fundamentalmente na definição de um modelo de comportamento "racional" frente a um conflito de interesses ou a um procedimento decisório. Seu estudo oferece subsídios teóricos que demonstram como a análise matemático-formal pode facilitar a tomada de decisões em grupo. A teoria dos jogos parte do pressuposto racionalista no qual as possibilidades são estabelecidas matematicamente. Ela pressupõe que os objetivos estejam definidos pelos participantes do jogo.
} 
sindicatos, meios de comunicação e outros membros da sociedade civil. Tais atores interagem em diversas "arenas", que podem ser formais (como o Legislativo), ou informais ("a rua"), e podem ter distintos graus de transparência (STEIN, 2007, p. 17).

A teoria dos ciclos elenca "cinco fases que permitem entender como uma política surge e se desenvolve: (i) percepção e definição do problema; (ii) inserção na agenda política; (iii) formulação; (iv) implementação; e (v) avaliação" (SCHMIDT, 2018, p. 131).

Por isso, é possível afirmar que a fase de formulação de políticas públicas baseia-se em "estudos prévios e em um sistema adequado de informações, definindo-se não só as metas, mas também os recursos e o horizonte temporal da atividade de planejamento" (SILVA; MELO, 2000, p. 14). No caso de políticas públicas voltadas para a sociedade, o processo de sua formulação deve "escutar" o contexto no qual se encontra inserido, buscando informações para a implementação adequada das mesmas.

Além disso, a formulação de políticas públicas enquanto atividade de planejamento sempre leva em consideração o objetivo que pretende atingir, bem como a finalidade almejada. Em se tratando de possibilitar o acesso à justiça e solucionar conflitos sociais, as políticas públicas podem ocorrer paralelas ao Poder Judiciário, ou serem anteriores ao processo judicial. Exemplo aqui é a conciliação/mediação - meios autocompositivos -, que podem acontecer antes ou depois da instauração do processo e, em se alcançando um acordo entre os conflitantes, este poderá ser homologado judicialmente se for objetivo produzir um título executivo judicial.

\section{Da autocomposição enquanto política pública de fomento ao direito fundamental de acesso à justiça}

A autocomposição enquanto política pública é mecanismo que pretende fomentar o acesso à justiça como direito humano fundamental mais do que simplesmente descongestionar o Judiciário diminuindo o número de demandas que a ele são direcionadas. O que se espera da autocomposição, é que contribua para um acesso à justiça mais adequado não só em termos quantitativos (celeridade e descongestionamento), mas também em termos qualitativos (adequação e exequibilidade da resposta jurisdicional).

Observa-se que a autocomposição é um ato volitivo das partes no sentido de resolver o conflito de maneira adequada alcançando o acesso à justiça na condição de "ordem jurídica 
justa" ${ }^{\prime 15}$. Fala-se de meios autocompositivos na medida em que os envolvidos no conflito assumem o risco e a responsabilidade da decisão que tomam, em consenso, ao lhe pôr um fim por meio de transação (acordo), desistência (renúncia a direito), submissão (reconhecimento jurídico do pedido), etc.

A autocomposição pode ocorrer por meio da mediação e da conciliação (SPENGLER; SPENGLER NETO, 2016), por exemplo, contando sempre com a participação de um terceiro imparcial que auxiliará nesse procedimento.

Assim, a autocomposição é uma forma autônoma (os titulares do poder de decidir a lide são as partes) de acesso à justiça e à jurisdição para resolver conflitos e atua com melhor eficiência quanto ao comprometimento dos interesses. Baseia-se em fatores persuasivos e consensuais, mediante os quais as partes compõem o litígio, de tal forma que obtêm soluções mais duradouras e exequíveis (BOLZAN DE MORAIS; SPENGLER, 2019).

Assim, o principal efeito da autocomposição "é fazer desaparecer o litígio. Se judicial, dá causa ao fim do processo; se preventiva, evita-o. Os escopos da autocomposição são os mesmos do processo, de natureza jurídica, social e política, tanto em relação aos envolvidos quanto, indiretamente, à sociedade” (CAHALI, 2015, p. 43).

A principal diferença entre autocomposição e heterocomposição diz respeito ao fato de que, enquanto nos processos heterocompositivos, cujos modelos são chamados adversariais (arbitragem e jurisdição) há sempre vencedores e vencidos (ganha/perde), nos processos autocompositivos de modelos consensuais (negociação, mediação e conciliação) buscam-se as soluções vencedoras (ganha/ganha), observando os interesses de todos (BACELLAR, 2011).

Dito dessa maneira, e com a expectativa de encontrar respostas adequadas aos conflitos, o objetivo principal da instituição das políticas públicas autocompositivas, ora em comento, é a participação dos conflitantes na busca de um direito fundamental de acesso à justiça cujo resultado atenda seus interesses, preservando o relacionamento prévio e os laços por ventura existentes entre eles. Nesse sentido, reduzir o volume de trabalho e de processos do Judiciário é apenas consequência daquele que é um importante resultado para a sociedade: $\mathrm{o}$ acesso à justiça de qualidade.

A autocomposição, ato de volitivo das partes no sentido de resolver o conflito, pode ocorrer por meio da mediação, da conciliação e da negociação, contando ou não com a participação de um terceiro imparcial, que poderá auxiliar nesse processo. Trata-se de uma

\footnotetext{
${ }^{15} \mathrm{O}$ primeiro item do texto discorre sobre o tema.
} 
forma autônoma (os titulares do poder de decidir a lide são as partes) de tratamento de conflitos, tal como a autotutela, atuando com mais eficiência quanto ao comprometimento dos interesses. Baseia-se em fatores persuasivos e consensuais, mediante os quais as partes compõem o litígio, de tal forma que obtêm soluções mais duradouras e exequíveis (BOLZAN DE MORAIS; SPENGLER, 2019).

Desse modo, a política pública de autocomposição, no atual CPC (aqui exemplificada pela mediação e pela conciliação) tem previsão de realização no âmbito do Poder Judiciário ou fora dele. Porém, conforme o CPC, deve ser utilizada sempre sob a fiscalização do Judiciário e pretende, dentre outras coisas, promover o direito fundamental de acesso à justiça construindo outra mentalidade junto aos juristas brasileiros cujo escopo principal seja a pacificação social, abandonando a cultura do litígio.

Assim, e conforme o já mencionado, a política pública de autocomposição objetivando fomentar o direito fundamental de acessar à justiça e oferecendo tratamento e resposta adequada (jurisdicional ou acordada entre as partes) ao conflito, apresenta vantagens (NOGUEIRA, 2011, p. 270) especialmente no que diz respeito:

a) ao melhor equacionamento da justiça, mediante a valorização da via préprocessual. Esse é o primeiro passo para o "restabelecimento da função secundária ou residual da jurisdição na solução de controvérsias" (NOGUEIRA, 2011, p. 270). Em resumo, a autocomposição (especialmente aqui a judicial) possibilitaria a aproximação das partes, a reapropriação do litígio pelas mesmas e a hipótese de tratá-lo, mediante o auxílio de um conciliador/mediador, de forma direta, autônoma e responsável, produzindo respostas adequadas e exequíveis.

A principal vantagem nesse momento é a reeducação dos conflitantes, dando a eles a noção de que podem (e devem!) resolver seus conflitos de maneira direta e pacífica, sem a intervenção do Estado, ultrapassando o paradigma da sentença para implementar e consolidar o paradigma do consenso e da efetiva pacificação social. Essa é a forma ideal de acesso à justiça.

b) acesso a uma ordem jurídica justa, que se dará pela disponibilização de vários meios autocompositivos, podendo os conflitantes escolher a que melhor se ajuste ao caso concreto. Na escolha do melhor método, a celeridade e a desburocratização oferecidas devem ser observadas, permitindo aos participantes a posição de protagonistas no processo decisório. 
c) qualidade dos serviços, que poderá ser alcançada a partir da exigência de capacitação de todos os envolvidos nos procedimentos, desde a coleta da reclamação até a realização das sessões de mediação e de conciliação. Além disso, a qualidade dos serviços também se evidenciará pela dedicação exclusiva de servidores e magistrados, pela unificação dos procedimentos, pela formação de um quadro único de mediadores e conciliadores, pelo gerenciamento dos conflitos a partir da adoção de políticas públicas de solução de massa e da aproximação gerencial de demandados e de demandantes.

d) a otimização de recursos do Poder Judiciário especialmente no que se refere ao espaço próprio, utilização de equipamentos de informática e instalações adequadas para o desenvolvimento de todas as atividades, bem como das sessões de mediação ou de conciliação.

Ao Judiciário é atribuída a tarefa de oferecer, nos termos do art. 334 do CPC e do art. 27 da Lei de Mediação, antes da solução adjudicada mediante sentença, outros mecanismos autocompositivos, em especial os chamados meios consensuais, como a mediação e a conciliação.

Esta prerrogativa vem reforçada pelo art. 165 do CPC no qual é possível avistar o compromisso dos tribunais em criar centros de solução consensual de conflitos, responsáveis pela realização de sessões e audiências de conciliação e mediação e pelo desenvolvimento de programas destinados a auxiliar, orientar e estimular a autocomposição.

Nesses termos, vislumbra-se um investimento na conscientização da necessidade de qualificar o acesso à justiça, investindo na autocomposição como meio de acessar uma resposta adequada em termos quantitativos e qualitativos objetivando, mais do que a pacificação do litígio pelas vias judiciais, a efetiva pacificação social. O resultado esperado é, também, a construção de uma cultura de autonomia e responsabilização dos litigantes.

Ao criar mecanismos de organização e estruturação da política pública de autocomposição (mediação e conciliação) o CPC também regra, em seu art. 176 caput e especialmente $\S 3^{\circ}$, o credenciamento, via cadastro, de câmaras privadas de conciliação e mediação para realização das sessões de mediações e conciliações, na forma do art. 334. Essas hipóteses são bem-vindas, porque os parceiros podem vir a resolver um grande problema: a falta de mediadores e conciliadores ${ }^{16}$ e o arejamento na elaboração e administração de cursos

\footnotetext{
16 Tal se dá principalmente pelas dúvidas quanto a implementação e o valor da remuneração (determinada também pelo art. 169 do CPC, pelo art. 13 da Lei 13.140/2015 e pela Resolução 271 do CNJ) e pelo fato de que
} 
de capacitação que, distanciados do Judiciário, poderão olhar suas dificuldades com completa isenção.

\section{Conclusão}

O congestionamento do judiciário brasileiro aponta para a necessidade de buscar outros caminhos para proporcionar ao cidadão o direito fundamental de acesso à justiça. Além disso, atualmente fica evidenciada a falta de respostas plausíveis, por parte das instituições estatais - dentre elas o Judiciário - frente às expectativas geradas não só pela criação de novos direitos, mas também perante a realidade econômica e social na qual os conflitos estão inseridos.

O acesso à justiça é direito humano fundamental, previsto na Constituição Brasileira 1988, que gradativamente vem sendo oferecido a população. O fomento aos serviços de justiça gratuita possibilitam a aproximação do cidadão. Porém, muitos entraves ainda existem, dentre eles a falta de celeridade processual.

Tais constatações permitem perceber que o acesso à justiça somente poderá ser dito "efetivo" se oferecer ao cidadão uma resposta adequada ao conflito e em tempo razoável.

Assim, frente às dificuldades de responder aos conflitos sociais de modo adequado, o CPC disciplinou a autocomposição como política pública fomentadora de acesso à justiça. Essa política pública vem sendo implementada também objetivando autonomizar os cidadãos envolvidos no litígio a ponto de alcançarem o consenso de forma conjunta, construindo uma resposta para o litígio que os une.

A autocomposição enquanto política pública de fomento ao direito fundamental de acesso à justiça é uma realidade, especialmente a partir da entrada em vigor do atual CPC. A necessidade da implementação dessa política pública aconteceu especialmente após a Constituição Federal de 1988 que valorizou o acesso à justiça além de garantir uma série de outros direitos. Informada a respeito, a população passou a ingressar com ações para proteger, reivindicar, garantir e assegurar direitos. Trabalhando sob essa delimitação de tema como eixo central o presente texto desenvolveu o objetivo proposto na sua introdução.

os conciliadores e mediadores ficam impedidos de desenvolver suas atividades profissionais em favor dos conflitantes. Diante desse quadro, corre-se o risco de perder os melhores profissionais, aqueles mais habilidosos, mais bem treinados e com conhecimento teórico profundo da matéria. 
Assim, respondendo o problema de pesquisa formulado, é possível afirmar que a autocomposição prevista no atual $\mathrm{CPC}$, é uma política pública de incetivo ao direito fundamental de acesso à justiça no Brasil, especialmente depois dos direitos assegurados na Contituição Federal de 1988.

\section{REFERÊNCIAS}

BACELLAR, Roberto Portugal. O Poder Judiciário e o paradigma da guerra na solução de conflitos. In: PELUSO, Antonio Cezar; RICHA, Morgana de Almeida (Coord). Conciliação e mediação: estruturação da Política Judiciária Nacional. Rio de Janeiro: Forense, 2011.

BOLZAN DE MORAIS, José Luis. As crises do Estado. In: MORAIS, José Luis Bolzan de (Org.). O Estado e suas crises. Porto Alegre: Livraria do Advogado, 2005. $\mathrm{bb}$

.; SPENGLER, Fabiana Marion. Mediação e arbitragem: Alternativas à jurisdição. $4^{\mathrm{a}}$ ed. Porto Alegre: Livraria do Advogado, 2019.

BUCCI, Maria Paula Dallari. O conceito de política pública em direito. In: Bucci, Maria Paula Dallari (Org.). Políticas públicas: reflexões sobre o conceito jurídico. São Paulo: Saraiva, 2006.

CAHALI, Francisco José. Curso de arbitragem: mediação, conciliação, resolução CNJ 125/2010. São Paulo: Revista dos Tribunais, 2015.

CANOTILHO, José Joaquim Gomes. O problema da responsabilidade do Estado por actos ilícitos. Coimbra: Livraria Almedina - Lael, 1987.

CAPPELLETTI, Mauro. GARTH, Bryant. Acesso à justiça. Porto Alegre: Sérgio Antonio Fabris Editor, 1988, reimpresso em 2002.

CHIOVENDA, Giuseppe. Dell'azione nascente dal contratto preliminare. In: Saggi di diritto processuale civile. Roma, Foro Italiano, 1930.

CONSELHO NACIONAL DE JUSTIÇA. Justiça em Números 2018: ano-base 2017. Brasília: Conselho Nacional de Justiça, 2018. Disponível em: <http://www.cnj.jus.br/pesquisas-judiciarias/justicaemnumeros/2016-10-21-13-13-04/pjjustica-em-numeros>. Acesso em: 13 de março de 2019.

DIAS, Reinaldo; MATOS, Fernanda. Políticas públicas. Princípios, propósitos e processos. São Paulo: Atlas, 2012.

GRAU, Eros Roberto. O direito e o direito pressuposto. 3. ed. São Paulo: Malheiros, 2000.

HOWLETT, Michael; RAMESH, M.; PERL Anthony. Política Pública, seus ciclos e subsistemas, uma abordagem integral. Tradução: Francisco G. Heidemann. 3 ed. Rio de Janeiro: Elsevier, 2013. 
MADERS, Angelita Maria. Acesso à justiça no Brasil: para quem? Direito em Debate. v. 14, n. 23, 25 mar. 2013.

MASSA-ARZABE, Patrícia Helena. Dimensão jurídica das políticas públicas. In: Bucci, Maria Paula Dallari (Org.). Políticas públicas: reflexões sobre o conceito jurídico. São Paulo: Saraiva, 2006.

MULLER P; SUREL Y. Crises de Politiques et régulations cognitives. Pôle Sud, n.4, 1996, pp. 92-106.

NOGUEIRA, Mariella Ferraz de Arruda Pollice. Dos núcleos permanentes de Métodos Consensuais de Solução de Conflitos. In: PELUSO, Antonio César; RICHA, Morgana de Almeida. Conciliação e mediação: estruturação da Política Pública Judiciária Nacional CNJ. Rio de Janeiro: Forense, 2011.

REIS, Elisa Pereira. Políticas e Políticas na Transição Democrática. 1989. Revista Brasileira. Rio de Janeiro, fev. 1989.

SCHMIDT, João Pedro. Para estudar políticas públicas: aspectos conceituais, metodológicos e abordagens teóricas. Revista do Direito. Santa Cruz do Sul, v. 3, n. 56, p. 119-149, set/dez. 2018 .

SILVA, Pedro Luís Barros; MELO, Marcus André Barreto de. O processo de implantação de políticas públicas no Brasil: características determinantes de avaliação de programas e projetos. In: Cadernos de pesquisa, n. 48, Núcleos de Políticas Públicas - NEPP; Unicamp, 2000.

SPENGLER, Fabiana Marion; LÍBIO, L. O Código de Ética de Conciliadores e Mediadores Judiciais. In: SPENGLER, F. M.; SPENGLER NETO, T. Mediação, conciliação e arbitragem: artigo por artigo. Rio de JANEIRO: Editora FGV, 2016. p. 159-175.

STEIN, E. et. al. (Coord.). A política das políticas públicas: progresso econômicos e social na América Latina: relatório 2006. Banco Interamericano de Desenvolvimento e David Rockefeller Center for Latin America Studies, Havard University. Tradução: Banco Interamerica de Desenvolvimento. Rio de Janeiro: Elsevier Washington, DC, 2007. 